\title{
Memória e Aprendizagem no Procedimento de Recordação Seletiva Livre e com Pistas
}

\author{
Murilo Ricardo Zibetti ${ }^{1}$ \\ Suelen Bordignon \\ Clarissa Marceli Trentini \\ Programa de Pós-Graduação em Psicologia, Instituto de Psicologia, \\ Universidade Federal do Rio Grande do Sul, Porto Alegre, Rio Grande do Sul, Brasil
}

\begin{abstract}
Resumo
O procedimento de Recordação Seletiva Livre e com Pistas (RSLP) é um importante método para avaliação da memória e da aprendizagem. O objetivo do estudo foi explorar a estrutura fatorial e verificar a aprendizagem através dos ensaios de um instrumento que utiliza este procedimento. Para isso, foram analisadas retrospectivamente as respostas de 83 idosos em uma tarefa que utiliza esse procedimento. Observou-se uma curva ascendente entre os ensaios na evocação livre, e que não há melhora significativa do desempenho após o segundo ensaio no total recordado (evocação livre mais evocação guiada por pistas). A estrutura fatorial observada foi de três fatores, sendo que os Fatores 1 e 2 sustentaram uma divisão entre escores de recuperação e de armazenamento da memória.O terceiro fator sugeriu a presença de um armazenamento temporário de informação. Tem-se como hipótese que o Fator 3 esteja relacionado ao buffer episódico da memória operacional. Esses resultados auxiliam na compreensão da RSLP e fornecem subsídios para o desenvolvimento de um novo teste de memória (Teste MAPS).
\end{abstract}

Palavras-chave: Memória, aprendizagem, recordação seletiva livre e com pistas, Teste de Buschke, Neuropsicologia.

\section{Memory and Learning in a Free and Cued Selective Reminding Procedure}

\begin{abstract}
The objective of the study was to verify, in an exploratory way, the factor structure and differences between each trial on instruments that use the procedure Free and Cued Selective Reminding (FCSR). The responses of 83 elderly people to FCSR were retrospectively analyzed. The results suggest that there is an ascending curve between almost all trials in a free recall and no significant differences after second trial in a total remembered. In addition, a three factor solution was observed. Factors 1 and 2 suggest maintaining a division between recovery and storage scores, while the presence of factor 3 suggests the presence of a score that asses a temporary storage of information. There is a hypothesis that factor 3 was related with episodic buffer in working memory. These results serve to better understanding the FCSR and used to develop a new memory test (MAPS Test).
\end{abstract}

Keywords: Memory, learning, free and cued selective reminding, Buschke Test, neupsychology.

Endereço para correspondência: Instituto de Psicologia, Universidade Federal do Rio Grande do Sul, Rua Ramiro Barcelos, 2600, sala 119, Bairro Santa Cecília, Porto Alegre, RS, Brasil 90035-003.E-mail: mrzibetti@, gmail.com, su.suelen@gmail.com e clarissatrentini@terra.com.br

Apoio financeiro: CNPq (Conselho Nacional de Desenvolvimento Científico e Tecnológico) e CAPES

(Comissão de Aperfeiçoamento de Ensino Superior). 


\section{Memoria y Aprendizaje en un Procedimiento de Recuerdo Selectivo Libre y Facilitado}

\section{Resumen}

El objetivo del estudio fué hacer una verificación exploratoria, de la estructura factorial y de las diferencias entre cada ensayo de los instrumentos que utilizan el procedimiento Recuerdo Selectivo Libre y Guiado (RSLG). Para hacer esto, se analizaron las respuestas de 83 personas mayores a una tarea con el RSLG.Se há observado una curva lineal y ascendente en lo recuerdo libre. No hubo diferencias significativas después del segundo ensayo en lo recuerdo facilitado. Se observó una estructura de tres factores. Factores 1 y 2 apoyaron una división entre la recuperación y el almacenamiento de la memoria. El tercer factor sugirió un almacenamiento de corto plazo de la información. Una hipótesis presentada fué de que el factor 3 se relaciona com el buffer episodico de la memoria de trabajo. Estos resultados sirven para entender mejor el RSLG y se utilizarán para desarrollar una nueva prueba de memoria (Test MAPS).

Palavras clave: Memoria, aprendizaje, recuerdo selectivo libre y facilitado, Prueba de Buschke, Neupsicología.

O Free and Cued Selective Reminding (recordação seletiva, livre e com pistas) é um procedimento amplamente utilizado para avaliação da memória e da aprendizagem, particularmente em idosos (Petersen, Smith, Kokmen, Ivnik, \& Talangos, 1992). Este trabalho teve como objetivo analisar a aprendizagem através dos ensaios e verificar a estrutura fatorial de uma tarefa de recordação seletiva livre e com pistas. Em última instância, esse estudo visa a colaborar para a construção de um instrumento denominado MAPS (Memória e Aprendizagem através de Pistas Seletivas) que está sendo construído para avaliar os mesmos construtos através de procedimentos similares. O MAPS será inspirado no Free and Cued Selective Reminding (FCSR) desenvolvido por Buschke (1984), aprimorado por Grober e Buschke (1987) e utilizado por Petersen et al. (1992).

Os instrumentos que utilizam o procedimento de recordação seletiva, livre e com pistas teriam como objetivo distinguir os prejuízos genuínos de memória (armazenamento) de outros prejuízos cognitivos que repercutiriam nos testes de memória (Grober, Ocepek-Welikson, \& Teresi, 2009). Isso seria possível devido ao controle das condições de aprendizagem proporcionadas pelo procedimento de recordação seletiva, livre e com pistas. Tal característica faz com que es- ses instrumentos sejam especialmente úteis no diagnóstico diferencial entre as demências e o declínio cognitivo normal associado ao envelhecimento (Buschke, 1984; Grober \& Buschke, 1987; Grober, Sanders, Hall, \& Lipton, 2010).

Na presente investigação, foi utilizada uma versão alternativa do FCSR, na qual o avaliando é apresentado a uma prancha com dezesseis figuras e é solicitado a localizar e a nomear cada estímulo a partir de uma categoria semântica fornecida pelo avaliador. Posteriormente, ele é solicitado a evocar livremente todos os itens que conseguir se lembrar. Para facilitar a recuperação dos itens não lembrados na evocação livre, o avaliador fornece uma pista semântica (categoria fornecida anteriormente). Esse procedimento ocorre durante seis ensaios consecutivos e, após 30 minutos, é realizada evocação livre e uma evocação com pistas (Petersen et al., 1992).

O processo controlado de procurar e localizar o estímulo através da categoria semântica garantiria que todos os estímulos fossem processados profundamente na cognição o que, segundo alguns teóricos, potencializaria o armazenamento na memória de longo prazo (Craik \& Lockhart, 1972; Henke, 2010; Magila \& Xavier, 1999). No entanto, esse efeito positivo sobre a memória de longo prazo só acontece, quando há uma transferência apropriada do processa- 
mento inicial da informação às condições de recuperação (Baddeley, Eysenck, \& Anderson, 2009). Esse funcionamento está na base teórica da criação da FCSR e é conhecido como princípio de codificação específica (Tulving \& Thomson, 1973). Ou seja, o efeito sobre a memória de longo prazo só é observado em contextos em que a recuperação é coordenada e apropriada à codificação. Dessa forma, a categoria fornecida na codificação, também serve como pista para os itens não lembrados na evocação livre, auxiliando na recuperação da informação que não pôde ser recordada livremente.

Conforme descrito anteriormente, apenas os itens não lembrados na evocação livre são reapresentados para o avaliando. Esse procedimento pode ser denominado como recordação seletiva (selective reminding; Buschke, 1973). A recordação seletiva permite uma maior organização subjetiva da informação, diminui o tempo de aplicação e a ansiedade dos participantes (Lezak, Howieson, \& Loring, 2004). Além disso, a recordação seletiva não apresenta diferenças estatisticamente significativas em relação aos escores gerados, quando comparada ao procedimento tradicional de avaliação da aprendizagem (MacLeod, 1985). Por isso, a recordação seletiva é considerada uma escolha parcimoniosa para avaliação da aprendizagem, visto que obtém resultados semelhantes com menor estresse do participante e em menor tempo de aplicação (MacLeod, 1985).

O FCSR é composto por estímulos pictóricos. Em geral, os estímulos visuais com significado (pictóricos) tendem a ser mais bem lembrados do que os estímulos apenas verbais. Ou seja, conter estímulos visuais também facilitaria a aprendizagem dos itens no teste. Provavelmente, isso ocorra devido a um efeito de dupla codificação dos itens. Ou seja, os estímulos pictóricos são codificados tanto de forma visual como de forma verbal, e isso aumentaria a possibilidade de serem memorizados, Esse efeito de superioridade das imagens em relação as palavras começou a ser comprovado em pesquisas da década de 1970 (Paivio \& Csapo, 1973). Atualmente, o efeito de superioridade das imagens já foi veri- ficado em idosos saudáveis (Cherry et al., 2008) em idosos com estágios iniciais da doença de Alzheimer (Ally, Gold, \& Budson, 2009). Por fim, o efeito de superioridade visual é relativamente estável em diferentes procedimentos de avaliação da memória, e pode ser notado no procedimento de recordação seletiva, livre e com pistas (Zimmerman et al., 2012).

Devido a esse controle e à facilitação das condições de aprendizagem, algumas pesquisas avaliaram a curva de aprendizagem e a estrutura latente dos instrumentos que utilizaram a recordação seletiva, livre e com pistas. Estudos norte americanos com o FCSR, por exemplo, verificaram que a cada ensaio, o número de itens evocados livremente aumenta (Petersen et al., 1992). No entanto, quando somados os itens lembrados na evocação livre com os evocados na evocação com pista a cada ensaio (total de itens lembrados a cada ensaio), observou-se um efeito de teto para a maioria dos avaliados (Petersen et al., 1992). Essa diferença entre itens evocados livremente e o total de itens recordado foi observada em praticamente todas as versões e estudos do procedimento de recordação seletiva livre e com pistas (Buschke, 1984; Grober \& Buschke, 1987; Grober et al., 2010; Petersen et al., 1992).

Quanto à estrutura fatorial, em um estudo com o FCSRT-IR ( Free and Cued Selective Reminding Test with Imediate Recall; Grober \& Buschke, 1987) que é semelhante ao utilizado no presente estudo, em geral, apresentava dois fatores. O primeiro fator era composto basicamente pelos escores da evocação livre dos itens em cada ensaio (Grober \& Buschke, 1987; Grober et al., 2009) e o segundo fator era composto pelo total recordado incluindo a evocação livre e a evocação com pistas (Grober \& Buschke, 1987).

Por fim, considerando a versão utilizada como um protótipo dos instrumentos que utilizam o controle das condições de aprendizagem, as diferenças entre evocação livre e evocação com pistas, optou-se por averiguar de forma empírica como é formada a curva de aprendizagem nos diferentes ensaios e qual a estrutura fatorial desse instrumento em uma amostra brasileira de 
idosos. As questões norteadoras da pesquisa foram: (a) existiriam diferenças significativas entre os seis ensaios, considerando tanto o número de itens da evocação livre quanto o total de itens recordados em cada ensaio?; (b) qual tipo de curva (linear, quadrática ou cúbica) descreveria melhor os ganhos (ou aprendizagem) a cada novo ensaio, tanto na evocação livre como no total recordado?; e (c) considerando uma análise exploratória, qual seria a estrutura fatorial do FCSR?. As respostas a essas perguntas auxiliariam na melhor compreensão dos processos de memória envolvidos no procedimento de recordação seletiva livre e com pistas. Esse entendimento poderá auxiliar nas tomadas de decisão para a construção de um instrumento de avaliação da memória denominado MAPS (que é inspirado no FCSR).

\section{Método}

\section{Procedimentos e Participantes}

Foram avaliados 83 participantes do interior do Rio Grande do Sul. Os dados foram coletados por profissionais da área da psicologia, treinados na aplicação dos instrumentos utilizados. Todos os participantes assinaram o Termo de Consentimento Livre e Esclarecido. Eram critérios de inclusão na amostra o auto-relato de ausência de doenças neurológicas ou dificuldades sensoriais não corrigidas. A avaliação ocorreu em uma única sessão, na residência do participante ou em local previamente combinado. Durante a avaliação, os participantes responderam em ordem aos seguintes instrumentos: Questionário Sócio-Demográfico (Trentini, Werlang, Xavier, \& Argimon, 2009); FCSR primeiros seis ensaios (Buschke, 1984; Grober \& Buschke, 1987; Petersen et al., 1992); Mini-exame do Estado Mental (versão de Bertolucci, Brucki, Campacci, \& Juliano, 1994); a tarefa Dígitos do WAIS-R (Wechsler, 1981); evocação tardia livre e com pistas do FCSR (Buschke, 1984; Grober \& Buschke, 1987; Petersen et al., 1992) e a Escala Geriátrica de Depressão (Yesavage, Brink, Rose, \& Lurn, 1983). Alguns instrumentos adicionais foram aplicados ao fim da sessão. Para este estu- do foram selecionados apenas os resultados dos dados demográficos e dos instrumentos descritos na seção seguinte que compuseram um novo banco.

\section{Instrumentos}

Para a descrição da amostra foram utilizados os dados do Questionário Sócio-demográfico (Trentini et al., 2009), a Escala Geriátrica de Depressão (Yesavage et al., 1983) e o Miniexame do Estado Mental (versão de Bertolucci et al., 1994). Os instrumentos utilizados na presente investigação e que compuseram a análises foram:

Subteste Dígitos da Escala Wechsler de Inteligência Revisada (WAIS-R; Wechsler, 1981): subteste solicita ao participante repetir na ordem direta e na ordem inversa os dígitos apresentados pelo examinador. $\mathrm{Na}$ ordem direta, esse subteste avalia atenção concentrada e retenção imediata. $\mathrm{Na}$ ordem inversa, avalia a capacidade de organização mental de informações e memória operacional.

Free and Cued Selective Reminding (Buschke, 1984; Grober \& Buschke, 1987; Petersen et al., 1992): o FCSR é um instrumento que utiliza o procedimento de recordação seletiva, livre e com pistas para avaliar a memória e o aprendizado. Nesse instrumento, 16 estímulos pictóricos de distintas categorias semânticas (ex.: desenho de um trem para categoria semântica de meios de transporte), são apresentados ao participante em uma única prancha de estímulos. O tempo de apresentação é livre e depende da velocidade do participante em encontrar e nomear cada um dos estímulos através de pistas semânticas dadas pelo avaliador (categorias). Após essa fase, denominada de estudo, a prancha de estímulos é retirada e é solicitada uma evocação livre dos itens aprendidos. Para facilitar a recordação daqueles estímulos que não foram evocados livremente, são fornecidas ao avaliando as mesmas pistas semânticas da fase de estudo. A aprendizagem é avaliada através da repetição de seis ensaios consecutivos do procedimento descrito.

A memória tardia é avaliada após $30 \mathrm{mi}-$ nutos e ocorre como nos demais ensaios, com a 
evocação livre seguida de evocação com pistas para os itens esquecidos. Esse instrumento gera os seguintes resultados: (a) total das evocações livre (EL) em cada um dos 6 ensaios $(1,2,3$, 4, 5 e 6) e na evocação livre tardia (ELTardia), formando os escores EL1, EL2, EL3, EL4, EL5, EL6 e ELTardia; (b) total recordado (T) considerando a soma da evocação livre mais evocação com pista em cada um dos seis ensaios $(1,2,3$, $4,5,6)$ e na evocação tardia (Tardia) formando os escores T1, T2, T3, T4, T5, T6 e TTardia; (c) somatório do total de evocações livres nos seis ensaios (SOL); (d) somatório do total recordado nos 6 ensaios (STR); (e) número de ensaios em que o participante recordou-se de todos os 16 estímulos, independentemente se isso ocorreu de forma livre ou com pista (LPMax).

\section{Análise de Dados}

Os dados demográficos foram analisados de forma descritiva e, posteriormente, foram realizadas duas análises sobre os resultados obtidos no FCSR. Primeiramente, foi conduzida uma ANOVA para medidas repetidas tanto para a evocação livre como para o total de itens lembrados. Nenhum desses escores apresentou esfericidade pelo teste de Mauchly $(p<0,01)$. Por isso, para análise do efeito principal entre os ensaios foi utilizada a correção de Greenhouse-Geisser. Além disso, devido ao grande número de análises derivadas da amostra também foi utilizada a correção de Bonferroni para a determinação do nível de significância.

A segunda análise foi realizada a partir do procedimento de análise de componentes principais com rotação Varimax. Esse procedimento é adequado para investigar, de forma exploratória, a estrutural fatorial dos escores gerados pelo FCSR.

Embora seja desejável um tamanho amostral maior (pelo menos 100 casos; Dancey \& Reidy, 2006), alguns autores indicam que uma amostra com 50 sujeitos seja um número mínimo, desde que exista pelo menos 5 participantes para cada variável analisada (Hair, Anderson, Tatham, \& Black, 2009). Além disso, a amostra mostrou índices tanto do $\mathrm{KMO}(0,911)$ quanto do teste de Bartlet $(p<0,01)$, compatíveis com o prosseguimento da análise fatorial. Cabe salientar, no entanto, que os escores compostos dos seis ensaios (somatório das evocações livres e somatório de todos os itens lembrados) foram retirados da análise por apresentarem grande colinearidade com os escores obtidos a cada ensaio. Entre os escores compostos, o único mantido foi o que indica o número de ensaios em que o participante lembrou-se de todos os 16 itens do instrumento.

\section{Resultados}

\section{Descrição da Amostra}

Os participantes tinham idade média de $74,20(D P=8,75)$ anos e a distribuição entre os sexos foi de 54 mulheres (61\%) para 29 homens. A média dos participantes no Mini-exame do Estado Mental foi $24,87(D P=4,08)$ e na Escala Geriátrica de Depressão foi 4,26 $(D P=3,48)$.

\section{ANOVA para Medidas Repetidas}

Foram observadas diferenças estatisticamente significativas entre os ensaios tanto na evocação livre $(F=61,486 ; p<0,001)$ quanto no total recordado $(F=8,792 ; p<0,001)$. Em ambos, a cada ensaio observou-se um aumento da média de itens lembrados, conforme pode ser observado na Figura 1.

Quanto à comparação entre os diferentes ensaios, foram conduzidas separadamente as análises da evocação livre e do total de itens recordados a cada ensaio. Em relação à evocação livre (EL) foram observadas diferenças significativas $(p<0,001)$ entre os seguintes ensaios: EL1 (todos os demais ensaios); EL2 (todos os demais ensaios); EL3 (ensaios 1, 2, 5 e 6); EL4 (ensaios 1, 2 e 6); EL5 (ensaios 1, 2 e 3); EL6 (ensaios 1, 2, 3 e 4); e, ELTardia (ensaios 1, 2 e 3). Em relação ao total de itens lembrados, foram observadas diferenças significativas $(p<0,001)$ apenas entre o escore $\mathrm{T} 1 \mathrm{e}$ os escores T5 e T6.

A curva mais adequada para descrever as diferenças na evocação livre, considerando apenas os seis primeiros ensaios, é linear e 


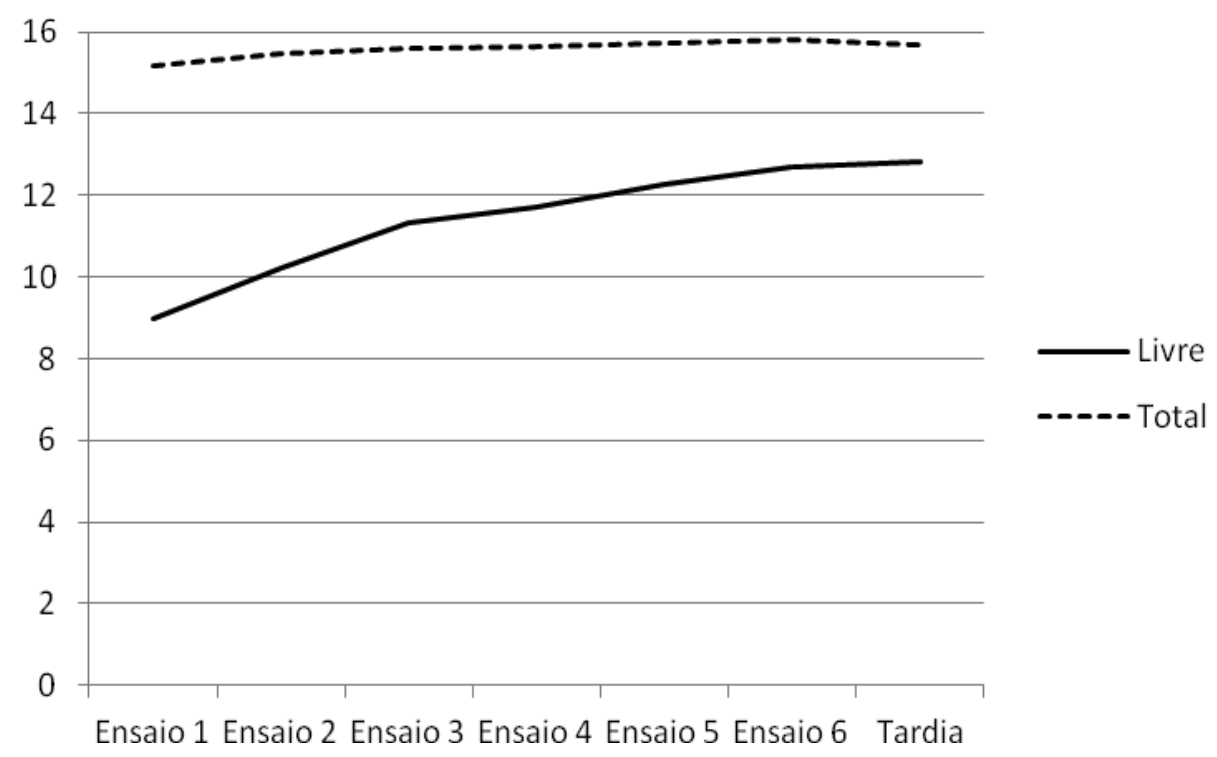

Figura 1. Média do número de itens em cada ensaio na evocação livre e no total recordado no FCSR.

ascendente $(F=219,257 ; p<0,001)$. Para o total recordado entre os ensaios, a mesma curva linear também descreve bem as diferenças entre os grupos $(F=14,681 ; p<0,001)$. No entanto, uma curva quadrática (com uma mudança angular), descreve de maneira adequada a diferença entre os ensaios $(F=11,816 ; p<0,001)$. Isso se deve ao efeito de teto observado no total de itens recordados a partir do segundo ensaio. Assim, a curva ascendente linear para o total de itens lembrados se deve ao aumento do número de participantes que obtém o máximo de itens a cada ensaio.

\section{Análise Fatorial Exploratória}

O processo de tomada de decisão quanto aos fatores gerados na análise levou em conta $o$ Eigenvalue $(>1)$, o percentual de explicação da variabilidade (maior que $4 \%$ ) e a observação do Scree Plot dos fatores. A solução fatorial mais adequada foi a de três fatores, que explicam $85,47 \%$ da variabilidade dos dados (a solução com 1 fator explica $64,39 \%$ e a solução com 2 fatores explica 78,45\% dos dados). Na Figura 2 está apresentado o Scree Plot dos fatores.

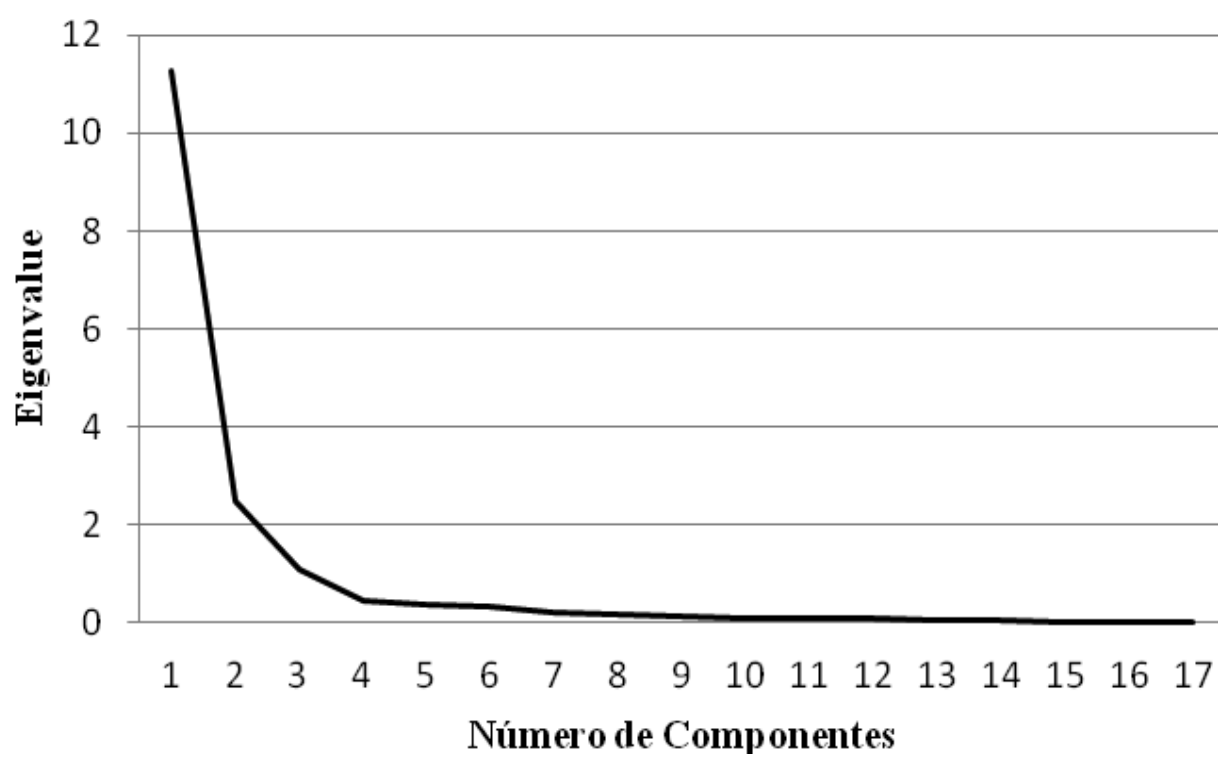

Figura 2. Scree Plot dos fatores no FCSR. 
Tabela 1

Cargas Fatoriais com Rotação Varimax no FCSR

\begin{tabular}{llll}
\hline \multicolumn{1}{c}{ Escores do FCSR } & Fator 1 & Fator 2 & Fator 3 \\
\hline Evocação Livre Ensaio 6 & 0,876 & & \\
Evocação Livre Ensaio 5 & 0,856 & 0,302 & \\
Evocação Livre Ensaio 4 & 0,855 & & \\
Evocação Livre Ensaio 3 & 0,848 & & \\
Evocação Livre Ensaio 2 & 0,815 & \\
Evocação Livre Ensaio 1 & 0,736 & & \\
Evocação Livre Tardia & 0,732 & 0,441 \\
Total Recordado Ensaio 6 & & 0,931 & 0,352 \\
Total Recordado Tardiamente & 0,371 & 0,886 \\
Total Recordado Ensaio 5 & & 0,874 \\
Total Recordado Ensaio 4 & & 0,874 \\
Total Recordado Ensaio 3 & & 0,816 \\
Total Recordado Ensaio 2 & & 0,624 \\
Total Recordado Ensaio 1 & 0,422 & 0,391 \\
Número de vezes em que foi recordado os 16 itens \\
(livres + pistas) (LPmax)
\end{tabular}

Nota. Legenda: FCSR (Free and Cued Selective Reminding). O método de rotação da análise fatorial foi Varimax com Normalização de Kaiser. Os valores negritados têm objetivo de mostrar qual dos fatores está relacionado com o escore apresentado.

$\mathrm{Na}$ Tabela 1 estão apresentadas as cargas fatoriais de cada um dos escores no instrumento. Para facilitar a visualização de cada fator foram omitidas cargas fatoriais inferiores a 0,300 .

Conforme a hipótese inicial, o Fator 1 e o Fator 2 agruparam em separado os escores de Evocação Livre e do Total Recordado. Um terceiro fator foi formado apenas pelo Total Recordado no primeiro ensaio (T1) e pelo escore do Número de vezes em que foi recordado os 16 itens (LPMax). Esses escores, embora agrupados, apresentam uma distinção teórica já que T1 representaria um armazenamento temporário da informação e o LPMax seria uma medida da eficiência do aprendizado através dos ensaios.

Ao observar essa incompatibilidade teórica e as importantes cargas fatoriais do LPMax nos demais fatores, uma segunda Análise Fatorial
Exploratória foi realizada. Nessa nova análise, todos os escores utilizados anteriormente foram mantidos e foram inseridos os dados obtidos pelos participantes na tarefa Dígitos do WAIS-R. O objetivo dessa análise foi verificar se o escore LPMax permaneceria associado ao Fator 3 , ao se inserirem escores que classicamente representam um armazenamento temporário de informação e sua manipulação dela na memória operacional.

Conforme a hipótese inicial, essa segunda análise fatorial demonstrou que o escore Dígitos do WAIS-R tinha cargas ínfimas para o primeiro e o segundo fator, mas uma carga moderada para o terceiro fator $(R=0,681)$, que também era composto pelo Total Recordado no Ensaio 1. Nesse sentido, ambos os escores parecem ser derivados da capacidade de um armazenamento temporário 
da informação como o que ocorre na memória operacional.

Por outro lado, o escore LPMax passou a ter carga fatorial superior para o primeiro fator. Esse resultado é compreensível, pois o escore LPMax parece dependente da eficiência do armazenamento menos efêmero e da recuperação das informações. A justificativa para que o escore LPMax tivesse se relacionado ao T1 é, provavelmente, o efeito de teto no total recordado a partir do segundo ensaio. Dessa forma, grande parte da variabilidade observada no LPMax é derivada do escore obtido no Total Recordado no Ensaio 1, associando-os em um único fator. No entanto, quando a variância de uma tarefa essencialmente de memória operacional é inserida no conjunto analisado (inserção do escore Dígitos), esse escore tende a se comportar como um escore que avalia um armazenamento menos efêmero do que o observado na memória operacional. Ou seja, o LPMax varia muito em decorrência do Total Recordado no Ensaio 1 , mas ele representa mais uma capacidade de aprendizado do que um armazenamento efêmero da informação.

\section{Discussão}

As questões que balizaram a presente investigação foram: (a) existiriam diferenças significativas entre os seis ensaios, considerando tanto o número de itens da evocação livre quanto o total de itens recordados em cada ensaio?; (b) qual tipo de curva (linear, quadrática ou cúbica) descreveria melhor os ganhos (ou aprendizagem) a cada novo ensaio tanto na evocação livre como no total recordado?; (c) considerando uma análise exploratória, qual seria a estrutura fatorial do FCSR?.

Em relação à evocação livre observa-se um efeito de aprendizagem através da repetição dos ensaios. Ou seja, o número de itens lembrados livremente aumenta a cada novo ensaio, apresentando uma curva linear de aprendizagem. Esse padrão é observado na evocação livre tanto em tarefas tradicionais (para exemplo, ver Malloy-Diniz, Lasmar, Gazinelli, Fuentes, \&
Salgado, 2007) como em tarefas que utilizam o procedimento de recordação seletiva (Petersen et al., 1992).

Quando se avalia apenas o total de itens recordados, são observadas diferenças significativas apenas entre os escores $\mathrm{T} 1 \mathrm{e}$ os escores $\mathrm{T} 5$ e T6. Esse resultado é condizente com a análise fatorial que aponta uma natureza diferente de armazenamento de informações no primeiro ensaio. Além disso, esses resultados sugerem que há um efeito de teto quanto ao total de itens lembrados a partir do segundo ensaio, apresentando-se uma curva de aprendizagem quadrática. Esse efeito de teto é observado para o total de itens lembrados em outros instrumentos que utilizam o procedimento de recordação seletiva, livre e com pistas (Grober \& Buschke, 1987; Petersen et al., 1992). Esse resultado pode refletir um excesso de facilitação nas condições de aprendizagem e de recuperação da informação, fazendo com que a maioria dos participantes lembre todos os itens quando somadas a evocação livre e a evocação com pistas.

Em relação à estrutura fatorial, não foram identificados estudos que analisassem os dados na versão utilizada do procedimento de recordação seletiva livre e com pistas. Por outro lado, estudos com um instrumento semelhante, o FCSRT-IR (Free and Cued Selective Reminding Test with Imediate Recall), apresentaram uma estrutura de dois fatores para a amostra clínica e de três fatores para a amostra saudável (Grober \& Buschke, 1987). A distribuição das variáveis entre os fatores ocorreu de forma muito semelhante à distribuição observada nos resultados do presente estudo. Ou seja, o primeiro fator correspondeu aos itens evocados de forma livre e o segundo fator correspondeu ao total de itens evocados (somando os evocados livremente e os evocados com pista). Observado apenas em saudáveis, o terceiro fator é composto pelo total de itens recordados no primeiro ensaio e um escore cuja variância esteve fortemente associada ao primeiro ensaio (Grober \& Buschke, 1987). Por essas características, os resultados do terceiro fator do FCSRT-IR indicaram o mesmo comportamento observado no presente estudo. 
Além disso, apenas os dados da evocação livre do FCSRT-IR foram reanalisados através de um procedimento de análise fatorial confirmatória (Grober et al., 2009). Esse estudo corroborou a hipótese de que os escores da evocação livre formariam um fator único que é mantido, inclusive, entre as versões paralelas do instrumento (Grober et al., 2009). Como não estavam no escopo da pesquisa os dados do total recordado, não foram analisados por Grober et al. (2009). Por fim, as estrutura fatoriais de dois instrumentos que utilizaram o procedimento de recordação seletiva livre e com pistas demonstraram grande semelhanças. O que pode indicar que, apesar de alterações na forma de aplicação, o procedimento de recordação seletiva, livre e com pistas avalia pelo menos esses dois construtos.

O Fator 1 e o Fator 2 dividiram, basicamente, os escores de evocação livre e os escores do total lembrado. Essa distinção mostrou que avaliariam aspectos distintos da memória (Grober \& Buschke, 1987). Esse aspecto pode ter relação com a dicotomia entre acessibilidade e disponibilidade da informação e representa basicamente que nem toda a informação armazenada é recuperada de forma livre e espontânea. Essa distinção pode refletir processamentos neurais distintos, essa hipótese pareceu ser corroborada por estudos de neuroimagem. A evocação livre, por exemplo, recrutaria áreas frontais à direita, associadas à estratégia de evocação, e a recordação através de pistas, ativaria áreas responsáveis por associações semânticas na região para-hipocampal em ambos os hemisférios cerebrais (Lekeu et al., 2003).

O total de itens recordados nos ensaios, que inicialmente foi apresentado como o escore mais útil na detecção de demências (Grober \& Buschke, 1987; Petersen et al., 1992), parece ser um melhor preditor de doença de Alzheimer (Grober et al., 2010). Enquanto isso, a evocação livre parece ser um preditor de outras demências, como a demência vascular (Grober et al., 2010). A codificação semântica, com posterior evocação livre e com pistas, também tem sido utilizada na distinção e avaliação de déficits de memória em pacientes com epilepsia unilateral à direita ou à esquerda (Lespinet-Najib et al., 2004). Por fim, a estrutura fatorial observada pode ser associada ao processamento de áreas distintas do cérebro, o que pode ser útil no diagnóstico diferencial de patologias neurológicas.

O terceiro fator observado na análise do FCSR é composto unicamente pelo Total de Itens Lembrados no primeiro ensaio (EL1). Esse escore pode representar um armazenamento temporário de informações. Essa hipótese parece pertinente, visto que o escore dos Dígitos da WAIS-R, que notadamente avalia memória operacional, tem uma carga expressiva para esse fator. Além disso, teoricamente o total de itens recordados no primeiro ensaio parece associar-se com o armazenamento do buffer episódico na memória operacional (Baddeley, 2000). O buffer episódico seria o responsável pelo processo de integração (binding) e armazenamento temporário de informações multi-modais (Baddeley, 2000, 2012; Canário \& Nunes, 2012). Essas informações seriam oriundas da alça fonológica, do esboço viso-espacial e da memória de longo prazo (Baddeley, 2000, 2012; Canário \& Nunes, 2012). No FCSR utilizado, essas informações são oriundas, respectivamente, do nome do estímulo, da representação pictórica do estímulo e da associação à categoria semântica.

Uma crítica a essa hipótese se deve ao fato de que apenas o escore T1 carrega no Fator 3. Seria bastante plausível supor que o escore de evocação livre nesse ensaio também iria compor o fator de memória "de curto prazo". Um contra-argumento é a possibilidade de que o resultado da evocação livre dos itens, independentemente do ensaio, esteja mais associado à formulação de estratégias de evocação do que propriamente ao mecanismo de armazenamento utilizado. Nesse caso, as pistas semânticas fornecidas no primeiro ensaio atuariam compensando a falta de acessibilidade das informações armazenadas no buffer episódico.

A hipótese da participação do buffer episódico em tarefas tradicionais de aprendizagem e memória que envolvem a repetição de ensaios foi investigada por diversos autores (Constantinidou, Danos, Nelson, \& Baker, 2011; Conway 
et al., 2005; Sander, Richardson, Constantinidou, Wertheimer, \& Paul, 2007). No entanto, a própria natureza e as funções do buffer episódico ainda não estão claramente determinadas na literatura, o que limita as interpretações sobre a relação desse componente com as tarefas cognitivas (Canário \& Nunes, 2012). Independentemente da participação do buffer episódico, a hipótese de um armazenamento temporário de informação é pertinente com a presença do Fator 3 no presente estudo. Esse fator já havia sido observado em outros estudos com o procedimento de recordação seletiva livre e com pistas (Grober \& Buschke, 1987), mas sua natureza teórica não havia sido explorada ainda. Essa hipótese pode e deve ser mais amplamente discutida em estudos posteriores.

Quanto à construção de um novo teste de memória que utilize o procedimento de recordação seletiva livre e com pistas (no caso, o teste MAPS) o presente estudo apresenta um ensaio inicial sobre a estrutura fatorial e a forma de aprendizagem no procedimento FCSR. As compreensões atingidas nesse estudo quanto às curvas de aprendizagem (linear para evocação livre e quadrática para evocação com pistas) e a estrutura fatorial (presença de três fatores) contribuem de diversas formas para o desenvolvimento teórico e psicométrico de um instrumento com o FCSR. Por exemplo, a constatação de que no total recordado, a curva de aprendizagem é quadrática, com um efeito de teto a partir do terceiro ensaio, suscita à reflexão sobre a necessidade de seis ensaios para avaliar a aprendizagem através da aprendizagem guiada. Outro aspecto a ser avaliado é a necessidade de utilizar os escores brutos, uma vez que a estrutura fatorial apresentou três fatores e que os índices têm alta carga fatorial. Sendo assim, a construção do teste MAPS poderia alterar algum dos procedimentos e escores para aumentar sua eficiência no uso do procedimento de recordação livre e com pistas.

Por fim, existem algumas limitações do estudo, de forma particular, quanto a interpretação da estrutura fatorial do FCSR. Primeiramente, a análise fatorial exploratória realizada possui um tamanho amostral apenas suficiente o que pode criar um viés sobre as cargas fatoriais. Além disso, trata-se de um estudo retrospectivo não projetado para essa análise, ou seja, o desenho de coleta não contemplou toda diversidade prescindida na análise fatorial e também não foram controlados os níveis de atividade diária e a possibilidade de algum participante ter um comprometimento cognitivo leve. No entanto, cabe lembrar que a análise fatorial indicou uma solução fatorial pertinente com os demais estudos da literatura (Grober \& Buschke, 1987; Grober et al., 2009), replicando o Fator 1 e o Fator 2 como associados, respectivamente, à estratégia de recuperação das informações e ao armazenamento de informações. Quanto ao Fator 3, mesmo que pouco explorado na literatura, já foi verificado em outras análises. A compreensão teórica desse fator foi guiada por uma análise fatorial posterior, corroborando a hipótese de estar associado a um armazenamento mais efêmero dos itens associado a memória operacional. Ou seja, apesar dos limites citados, o estudo pôde fornecer alguns esclarecimentos quanto aos processos cognitivos de memória e de aprendizagem subjacentes ao FCSR e também, pelos resultados semelhantes, sobre o procedimento de recordação livre e com pista.

\section{Referências}

Ally, B. A., Gold, C. A., \& Budson, A. E. (2009). The picture superiority effect in patients with Alzheimer's disease and mild cognitive impairment. Neuropsychologia, 47, 595-598. doi:10.1016/j.neuropsychologia.2008.10.010

Baddeley, A. (2000). The episodic buffer: A new component of working memory? Trends in Cognitive Sciences, 4(11), 417-423. doi:10.1016/ S1364-6613(00)01538-2

Baddeley, A. (2012). Working memory: Theories, models, and controversies. Annual Review of Psychology, 63, 1-29. doi:10.1146/annurevpsych-120710-100422

Baddeley, A., Eysenck, M. W., \& Anderson, M. C. (2009). Memory. New York: Psychology Press.

Bertolucci, P. H. F., Brucki, S. M. D., Campacci, S. R., \& Juliano, Y. (1994). O Mini-exame do Estado Mental em uma população geral: Impacto 
da escolaridade. Arquivos de Neuropsiquiatria, $52,1-7$.

Buschke, H. (1973). Selective reminding for analysis of memory and learning. Journal of Verbal Learning and Verbal Behavior, 12(5), 543-550. doi:10.1016/S0022-5371(73)80034-9

Buschke, H. (1984). Cued recall in amnesia. Journal of Clinical Neuropsychology, 6(4), 433-440. doi:10.1080/01688638408401233

Canário, N., \& Nunes, M. V. S. (2012). Buffer episódico 10 anos depois. Revista Neurociência, 20(2), 311-319.

Cherry, K. E., Hawley, K. S., Jackson, E. M., Volaufova, J., Su, L. J., \& Jazwinski, S. M. (2008). Pictorial superiority effects in oldest-old people. Memory, 16(7), 728-741. doi:10.1080/09658210802215534

Constantinidou, F., Danos, M. A., Nelson, D., \& Baker, S. (2011). Effects of modality presentation on working memory in school-age children: Evidence for the pictorial superiority hypothesis. Child Neuropsychology, 1, 1-24. doi:10.10 80/09297049.2010.525503

Conway, A., Kane, M., Bunting, M., Hambrick, D., Wilhelm, O., \& Engle, R. (2005). Working memory span tasks: A methodological review and user's guide. Psychonomic Bulletin \& Review, 12, 769-786.

Craik, F. I. M., \& Lockhart, R. S. (1972). Levels of processing: A framework for memory research. Journal of Verbal Learning and Verbal Behavior 11, 671-684. doi:10.1016/S0022$-5371(72) 80001-\mathrm{X}$

Dancey, C. P., \& Reidy, J. (2006). Estatística sem Matemática para Psicologia (3. ed.). Porto Alegre, RS: Artmed.

Grober, E., \& Buschke, H. (1987). Genuine memory deficits in dementia. Developmental Neuropsychology, 3(1), 13-36. doi:10.1080/87565648709540361

Grober, E., Ocepek-Welikson, K., \& Teresi, A. J. (2009). The Free and Cued Selective Reminding Test: Evidence of psychometric adequacy. Psychology Science Quarterly, 51(3), 266-282.

Grober, E., Sanders, A. E., Hall, C., \& Lipton, R. B. (2010). Free and Cued Selective Reminding Identifies very mild dementia in primary care. Alzheimer Disease Associated Disorder, 24(3), 284-290.
Hair, J. F., Anderson, R. E., Tatham, R. L., \& Black, W. C. (2009). Análise multivariada de dados (6. ed.). Porto Alegre, RS: Bookman.

Henke, K. (2010). A model for memory systems based on processing modes rather than consciousness. Nature Reviews - Neuroscience, 11, 523-532. doi:10.1038/nrn2850

Lekeu, F., Van der Linden, M., Chicherio, C., Collette, F., Degueldre, C., Franck, G., ...Salmon, E. (2003). Brain correlates of performance in a Free/ Cued recall task with semantic encoding in Alzheimer disease. Alzheimer Disease Associated Disorder, 17(1), 35-45. doi:10.1097/00002093200301000-00005

Lespinet-Najib, V., N'Kaoua, B., Sauzèo, H., Bresson, C., Rougier, A., \& Claverie, B. (2004). Levels of processing with free and cued recall and unilateral temporal lobe epilepsy. Brain and Language, 89, 83-90. doi:10.1016/S0093$-934 X(03) 00303-1$

Lezak, M. D., Howieson, D. B., \& Loring, D. W. (2004). Neuropsychological assessment $\left(4^{\text {th }}\right.$ ed.). New York: Oxford Universiry Press.

MacLeod, C. M. (1985). Learning a list for free recall: Selective reminding versus standard procedure. Memory \& Cognition, 13(3), 233-240. doi:10.3758/BF03197686

Magila, M. C., \& Xavier, G. F. (1999). Modelos de memória de longa duração em humanos. Psicologia: Teoria e Pesquisa, 15(1), 37-44.

Malloy-Diniz, L. F., Lasmar, V. A. P., Gazinelli, L. S. R., Fuentes, D., \& Salgado, J. V. (2007). Teste de Aprendizagem Auditivo-verbal de Rey: Aplicabilidade na população idosa brasileira. Revista Brasileira de Psiquiatria, 29(4), 324-329.

Paivio, A., \& Csapo, K. (1973). Picture superiority in free recall: Imagery or dual coding? Cognitive Psychology, 5, 176-206. doi:10.1016/00100285(73)90032-7

Petersen, R. C., Smith, G., Kokmen, E., Ivnik, R. J., \& Talangos, E. G. (1992). Memory function in normal aging. Neurology, 42, 396-401.

Sander, A. M., Richardson, R., Constantinidou, F., Wertheimer, J., \& Paul, D. (2007). Memory assessment on an interdisciplinary rehabilitation team: A theoretically based framework. American Journal of Speech-Language Pathology, 16, 316-330. doi:10.1044/10580360(2007/036) 
Trentini, C. M., Werlang, B. S. G., Xavier, F. M. F., \& Argimon, I. I. L. (2009). A relação entre variáveis de saúde mental e cognição em idosos viúvos. Psicologia: Reflexão e Crítica, 22(2), 224-236.

Tulving, E., \& Thomson, D. M. (1973). Encoding specificity and retrieval processes in episodic memory.Psychological Review, 80(5), 352-373. doi:10.1037/h0020071

Wechsler, D. (1981). The Wechsler Adult Intelligence Scale-Revised. San Antonio, TX: The Psychological Corporation.

Yesavage, J. A., Brink, T. L., Rose, T. L., \& Lurn, O. (1983). Development and validation of a geriatric depression screening scale: A preliminary report. Journal of Psychiatry Resources, 17, $37-$ 49. doi:10.1016/0022-3956(82)90033-4
Zimmerman, M., Katz, M., Wang, C., Burns, L., Berman, R., Derby, C., ...Lipton, R. (2012). Comparison of the 'word' $v s$. 'picture' versions of the free and cued selective reminding test (FCSRT) in older adults [Abstract]. Alzheimer's \& Dementia: The Journal of the Alzheimer's Association, 8(4), 367. doi:10.1016/j.jalz.2012.05.1004

Recebido: 13/11/2013

$1^{a}$ revisão: $27 / 03 / 2014$

Aceite final: 11/04/2014 